\title{
Development of a chemically defined cultivation and transfection medium for HEK cell lines
}

\author{
Sebastian Püngel' ${ }^{1}$, T Tim Welsink', Penélope Villegas Soto', Wolfgang Weglöhner', Tim F Beckmann², \\ Ina Eickmeier ${ }^{2}$, Stefan Northoff ${ }^{2}$, Christoph Heinrich ${ }^{2}$ \\ From 23rd European Society for Animal Cell Technology (ESACT) Meeting: Better Cells for Better Health \\ Lille, France. 23-26 June 2013
}

\section{Background}

In the process of generating a production cell, introduction of the gene of interest into the host cell can be performed by various physical, chemical or biological methods. Because of the greater scalability compared to physical methods and no safety concerns or restrictions that are associated with the use of viral systems, a transfection using chemical methods is of great interest. However, up to now up-scaling is limited by the challenge to transfect cells in conditioned media with the widely used reagent polyethylenimine (PEI). Considering the upscaling to gram yields, a culture medium that allows both, transfection and production is required. In this work, the current status in the development of such media supporting cell growth, transfection and protein production in HEK cells is presented. By this, processes will no longer be limited by media exchange prior transient transfection.

\section{Materials and methods}

Transfection was performed according to standard protocols described in the literature. Briefly, $5 \times 10^{6}$ cells $/ \mathrm{mL}$ were transfected with $2 \mathrm{pg} \mathrm{DNA} / \mathrm{cell}$ and $25 \mathrm{kDa} \mathrm{PEI}$ in $4 \mathrm{~mL}$ transfection volume. Transfection efficiency was determined 24 hours post transfection by counting green fluorescent positive cells using a FACSCalibur (BD Biosciences). All cultivations were carried out using shake flasks with standard conditions well known in the art. Automated viable cell counting was performed by a Cedex (Innovatis). Furthermore, the quantities of components like glucose, lactate, amino acids, salts and vitamins in the supernatant were measured. Based on this information, single ingredients or groups of components from the basal formulation were screened for their influence

\footnotetext{
* Correspondence: Christoph.Heinrich@teutocell.de

${ }^{2}$ TeutoCell AG, 33615 Bielefeld, Germany

Full list of author information is available at the end of the article
}

on transfection efficiency. To evaluate the effect of cellular proteins in conditioned medium, they were separated by chromatography and analyzed via MALDI-TOF/TOF mass spectrometry (MS) (ultrafleXtreme, Bruker). SEC was performed using the high resolution gel filtration medium Superdex ${ }^{\mathrm{TM}} 20016 / 60$ with the ÄKTAprime system (GE Healthcare).

\section{Results}

Batch growth for an exemplary HEK host cell line in the latest basic growth medium formulation reached a maximum viable cell density of nearly $1 \times 10^{7}$ cells $/ \mathrm{mL}$. Direct adaption of three different adherent serumdepending host cell lines was also successfully implemented in this medium. The screening of basal medium components exhibited no significant influence on transient transfection efficiency of HEK cells (overall efficiency of $80 \%+/-15 \%$ ), as shown in Figure 1(A). In contrast, depending on the level of conditioning, the presence of proteins in the supernatant of these media reduced transfection efficiency up to $100 \%$ (Figure 1B).

Separation and analysis of conditioned medium revealed that especially high molecular weight components have a negative impact on the transfection efficiency. Identification by MALDI-TOF/TOF-MS showed not only proteins of the basal lamina but also histones to be present in the analyzed high molecular weight fractions 1 and 2 (Table 1 ).

\section{Conclusions}

The latest medium formulation supports cell growth and easy adaption to suspension of the three major HEK host cell lines and several producer cell lines originated from those. High transfection efficiencies of up to $80 \% 24$ hours post transfection where reached in a basic medium formulation. In this context, the major challenge for combining 


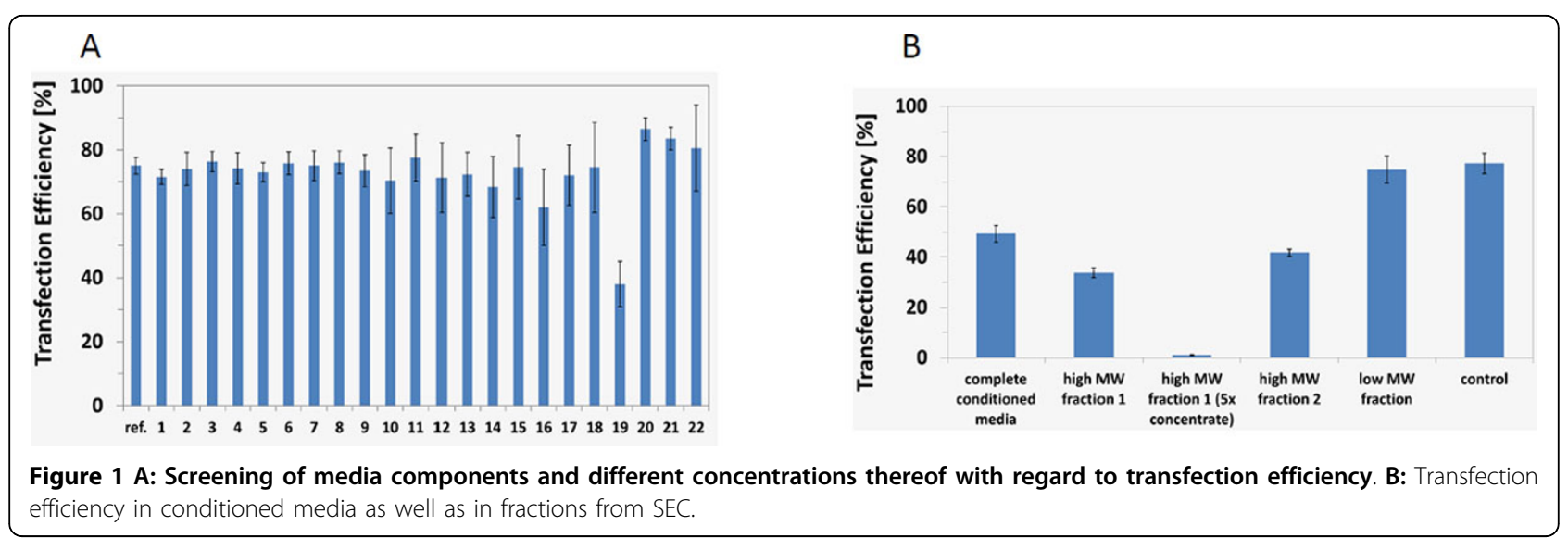

Table 1 Proteins identified with at least 2 peptides and a false discovery rate of $0 \%$ in up to 5 biological replicates by MALDI-TOF/TOF-MS in the high molecular weight fractions 1 and 2.

\begin{tabular}{|c|c|c|c|c|c|}
\hline \multicolumn{3}{|c|}{ High molecular weight fraction 1} & \multicolumn{3}{|c|}{ High molecular weight fraction 2} \\
\hline Group & Protein name & \# Peptides & Group & Protein name & \# Peptides \\
\hline \multirow[t]{3}{*}{ Histones } & Histone $\mathrm{H} 2 \mathrm{~A}$ & 3 & Histones & Histone $\mathrm{H} 2 \mathrm{~A}$ & 4 \\
\hline & Histone H2B & 2 & & Histone $\mathrm{H} 2 \mathrm{~B}$ & 3 \\
\hline & Histone H4 & 2 & & Histone H4 & 4 \\
\hline & & & & Histone $\mathrm{H} 3$ & 3 \\
\hline \multirow[t]{3}{*}{ Cytoskeleton } & Tubulin alpha & 2 & 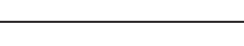 & 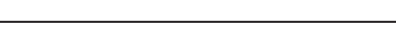 & \\
\hline & Tubulin beta & 2 & Cytoskeleton & Tubulin alpha & 2 \\
\hline & Actin & 3 & & Tubulin beta & 3 \\
\hline & & & & Actin & 6 \\
\hline \multirow[t]{9}{*}{ Other } & Galectin-3-binding protein & 6 & (2) & & \\
\hline & Heat shock 70 kDa protein 1A/1B & 5 & Extracellular (matrix) & Fibrillin-2 & 2 \\
\hline & & & & Fibronectin & 5 \\
\hline & & & & Clusterin & 3 \\
\hline & & & & Cochlin & 2 \\
\hline & & & Other & Galectin-3-binding protein & 10 \\
\hline & & & & Heat shock $70 \mathrm{kDa}$ protein $1 \mathrm{~A} / 1 \mathrm{~B}$ & 13 \\
\hline & & & & Golgi membrane protein 1 & 6 \\
\hline & & & & Alpha-enolase & 2 \\
\hline
\end{tabular}

a transfection- and growth medium in one formulation is to retain single cell growth, while avoiding commonly used anti-aggregation components, which are known to impair transfection efficiency. Beyond that, in this study basal medium components exhibited no influence on transient transfection, whereas high molecular weight fractions of conditioned media reduced transfection efficiency. Noticeably, these fractions contained histones which might be one factor with negative impact.

\section{Authors' details}

${ }^{1}$ InVivo BioTech Services GmbH, 16761 Hennigsdorf, Germany. ${ }^{2}$ TeutoCell AG, 33615 Bielefeld, Germany.

Published: 4 December 2013

doi:10.1186/1753-6561-7-S6-P27

Cite this article as: Püngel et al:: Development of a chemically defined cultivation and transfection medium for HEK cell lines. BMC Proceedings 2013 7(Suppl 6):P27. 